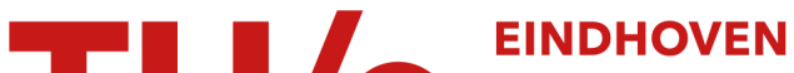 UNIVERSITY OF TECHNOLOGY
}

\section{Optical Characterization of Plasma-Deposited SiO2-like Layers on Anisotropic Polymeric Substrates}

\section{Citation for published version (APA):}

Aresta, G., Premkumar, P. A., Starostin, S. A., Vries, de, H., Sanden, van de, M. C. M., \& Creatore, M. (2009). Optical Characterization of Plasma-Deposited SiO2-like Layers on Anisotropic Polymeric Substrates. In Proceedings of the 56th international American Vacuum Society Symposium \& Exhibition (AVS 56) 8-13 November 2009, San Jose, California (pp. AS+EM+MS+TF-TuM1-43). AVS.

Document status and date:

Published: 01/01/2009

\section{Document Version:}

Publisher's PDF, also known as Version of Record (includes final page, issue and volume numbers)

\section{Please check the document version of this publication:}

- A submitted manuscript is the version of the article upon submission and before peer-review. There can be important differences between the submitted version and the official published version of record. People interested in the research are advised to contact the author for the final version of the publication, or visit the $\mathrm{DOI}$ to the publisher's website.

- The final author version and the galley proof are versions of the publication after peer review.

- The final published version features the final layout of the paper including the volume, issue and page numbers.

Link to publication

\section{General rights}

Copyright and moral rights for the publications made accessible in the public portal are retained by the authors and/or other copyright owners and it is a condition of accessing publications that users recognise and abide by the legal requirements associated with these rights.

- Users may download and print one copy of any publication from the public portal for the purpose of private study or research.

- You may not further distribute the material or use it for any profit-making activity or commercial gain

- You may freely distribute the URL identifying the publication in the public portal.

If the publication is distributed under the terms of Article 25fa of the Dutch Copyright Act, indicated by the "Taverne" license above, please follow below link for the End User Agreement:

www.tue.nl/taverne

Take down policy

If you believe that this document breaches copyright please contact us at:

openaccess@tue.nl

providing details and we will investigate your claim. 


\section{Tuesday Morning, November 10, 2009}

\section{Applied Surface Science \\ Room: C2 - Session AS+EM+MS+TF-TuM}

\author{
Spectroscopic Ellipsometry III \\ Moderator: M. Schubert, University of Nebraska - Lincoln
}

8:00am AS+EM+MS+TF-TuM1 Optical Characterization of PlasmaDeposited $\mathrm{SiO}_{2}$-like Layers on Anisotropic Polymeric Substrates, G. Aresta, Eindhoven Univ. of Tech., The Netherlands, A.P. Premkumar, Materials Innovation Inst. (M2i), The Netherlands, S.A. Starostin, Eindhoven Univ. of Tech., The Netherlands, H. de Vries, FUJIFILM Mfg Europe B.V, The Netherlands, M.C.M. van de Sanden, M. Creatore, Eindhoven Univ. of Tech., The Netherlands

Amongst the most common thin film characterization tools, spectroscopic ellipsometry (SE) is increasingly used to determine the layer optical properties. Such characterization is still a challenge when optical anisotropy is present either in the film or in the substrate. The study of thin films deposited on polymeric substrates is an example because polymers often show optical anisotropy. In this contribution the optical characterization of poly(ethylene 2,6-naphtalate) (PEN) in its transparent region is carried out by means of Transmission Generalized Ellipsometry (TGE) and reflection multi- angle SE measurements. TGE measurements allow the determination of the in-plane and out-of-plane anisotropy and orientation of the material index ellipsoid, with respect to the laboratory frame. Reflection multi-angle SE measurements are performed to determine the absolute refractive index values along the $\mathrm{x}, \mathrm{y}$ and $\mathrm{z}$ directions (i.e. the laboratory frame). The full optical characterization of PEN substrates has been carried out first by identifying its in plane anisotropy (i.e. $\Delta n_{x y}=n_{y}-n_{x}$ ) and in-plane orientation of the material index ellipsoid with respect to the $\mathrm{x}$ axis, by means of TGE measurements at $0^{\circ}$ angle of incidence. A second step consisting of TGE measurements at different angles of incidence has allowed the determination of the out-of-plane anisotropy (i.e. $\Delta n_{x z}=n_{x}-n_{z}$ ) and the material index ellipsoid out-of-plane orientation with respect to the $\mathrm{z}$ axis. Finally, reflection multi angle measurements have allowed the determination of the optical dispersions along the three axes $(\mathrm{x}, \mathrm{y}, \mathrm{z})$. The values of the refractive index calculated at $633 \mathrm{~nm}$ are $n_{x}=1.74, n_{y}=1.75$ and $n_{z}=1.52$. This characterization is functional to the determination of the refractive index of plasma-deposited $\mathrm{SiO}_{2}$-like layers deposited on PEN substrates. The $\mathrm{SiO}_{2}$-like samples have been deposited in Atmospheric Pressure Glow discharges [1,2] from $\mathrm{Ar} / \mathrm{O}_{2} /$ hexamethyldisiloxane mixtures at different duty cycles. SE measurements have been performed in ambient air and in vacuum: an increase of the refractive index values with the duty cycle has been observed, attributed, on the basis of complementary diagnostics, to an increase in film density with the duty cycle.

References:

[1] S. Starostine, E. Aldea, H. de Vries, M. Creatore, M. C. M. van de Sanden Plasma

Process. Polym. 4, S440-S444 (2007)

[2] S. A. Starostin, M.A. M. El Sabbagh, E. Aldea, H. de Vries, M. Creatore, and M. C. M. van de Sanden

IEEE transactions on Plasam Science, 36, 4, (2008)

8:20am AS+EM+MS+TF-TuM2 Spectroscopic Ellipsometry in the Mid IR and UV-VIS for Investigating Low Temperature Plasma Activated Wafer Bonding, T. Plach, K. Hingerl, University Linz, Austria, V. Dragoi, M. Wimplinger, EV Group, Austria

Low temperature plasma activated direct wafer bonding (LTPADWB) for $\mathrm{Si}-\mathrm{SiO}_{2}$ interfaces is a process that lowers the required annealing temperatures, (from usually $900^{\circ} \mathrm{c}$ down to $250^{\circ} \mathrm{C}$ ) necessary for reaching high bond strength. The mechanism behind this improvement is still under discussion: The low temperature steps for the hydrophilic process are interpreted as follows: $\mathrm{Up}$ to $100^{\circ} \mathrm{C}$ the substrate surfaces are held together via van der Waals interaction which is mediated by a few monolayers of water. In the range of $100-200^{\circ} \mathrm{C}$ the water diffuses away from the interface both along the interface and through the oxide into the crystalline bulk, where it reacts with the silicon and forms oxide. The remaining half of the bond strength is usually attributed to a closing of gaps at the interface[1], which starts with conventional techniques at the softening temperature of the thermal oxide at around $850-900^{\circ} \mathrm{C}$.

In comparison the same surface energies for the LTPADWB process are already reached at $250^{\circ} \mathrm{C}$. To clarify the mechanism for this process, different bonding experiments were performed to evaluate the lifetime of the surface activation and the achievable bond strength when using substrates with various orientations. By covering half of the wafer during plasma activation, comparisons between the activated and non-activated region could be made by mid IR and UV-VIS spectroscopic ellipsometry covering the energy range from phonon energies to the UV $(30 \mathrm{meV}$ $6.5 \mathrm{eV})$. it turns out that the spectral shape of the phonon peaks as well as the spectral shape of the critical points in the UV $\left(E_{1}, E_{2}\right)$ significantly change and even the peak position changes.

Correlation measurements, by Auger analysis and by X-ray photoelectron spectroscopy.Interfaces of bonded wafer pairs have been performed in addition, as well as by transmission electron microscopy (TEM). TEM clearly shows that there is no discernible interface between the native oxide on one side and the thermal oxide on the other side.

From the spectroscopic ellipsometry data it was found that the top surface stoichiometry is chemically changed, which favors bonding. Finally a model for the mechanism that explains the experimental results will be presented.[1] Q.-Y. Tong, U. Gösele, Semiconductor Wafer Bonding: Science and Technology, Wiley

8:40am AS+EM+MS+TF-TuM3 Applications of Ellipsometry and Polarimetry to Real-Time Analysis and Control of Epitaxial Growth, D.E. Aspnes, North Carolina State University and Kyung Hee University, Korea

INVITED

Many aspects of epitaxial growth are now mainstream technologies, routine enough so that real-time monitoring simply gets in the way. However, the situation is different in emerging areas involving the heteroepitaxy of chemically or lattice-mismatched materials, where paths to success through kinetics and thermodynamics are not well understood, or even identified. Here, real-time analysis and control by ellipsometry or polarimetry not only can provide unique information but may also be essential in achieving objectives. In particular, these techniques can provide information about the critical initial stages of growth well down into the submonolayer scale in addition to the evolution of growth beyond the first monolayer. Further, analysis of data records allows diagnostics to be performed after the fact, permitting detailed analyses of processes that went wrong -- or right. I provide examples from our experiences with organometallic chemical vapor deposition, including sample-driven feedback-control of composition and the analysis of the initial phases of epitaxy of such diverse systems of $\mathrm{GaSb}$ on $\mathrm{GaAs}, \mathrm{GaP}$ on $\mathrm{Si}$, and $\mathrm{ZnO}$ on sapphire. The latter application involves a material whose precursors react in the gas phase and where the product sublimes. Real-time polarimetric data provided the information needed to grow high quality material.

9:20am AS+EM+MS+TF-TuM5 Spectroscopic Ellipsometric Sudy of Phase-Change Materials for Data Storage Applications, E. Gourvest, STMicroelectronics, France, $C$. Vallée, LTM - CNRS/UJF/INPG, France, $S$. Lhostis, STMicroelectronics, France, Ch. Licitra, A. Roule, CEA - LETI, France, B. Pelissier, LTM - CNRS/UJF/INPG, France, S. Maitrejean, CEA - LETI, France

Chalcogenide materials are widely used for phase change data storage based on the remarkable change of properties between the crystalline and the amorphous phase. The fast and reversible phase transition is accompanied by a high electrical and optical contrast and consequently a change of electronic structure which is still not well understood. In this work we present the optical function spectra of different phase-change materials. $\mathrm{Ge}_{2} \mathrm{Sb}_{2} \mathrm{Te}_{5}$, Ge-doped GeTe and N-doped GeTe films were grown by cosputtering PVD method on $200 \mathrm{~mm}$ wafers and were treated with different annealing temperatures. Film thickness, oxydation and composition were evaluated using X-Ray Reflectivity, Rutherford BackScattering and Angle Resolved XPS.

Optical parameters were fitted from data measured by variable angle spectroscopic ellipsometry. Measurements were carried out between 0.5 and $8 \mathrm{eV}$ for $\mathrm{Ge}_{2} \mathrm{Sb}_{2} \mathrm{Te}_{5}$ samples in amorphous, fcc and he crystalline phases in order to characterize phase-change bulk layer and surface oxide layer. Ge doped $\mathrm{GeTe}$ and $\mathrm{N}$-doped GeTe samples were measured between 0.6 and 6 $\mathrm{eV}$ for amorphous and rhombohedral phases.

$\mathrm{Ge}, \mathrm{Sb}$ and Te thin films are also elaborated by PVD in order to obtain optical laws for the different elements and well defined the optical response of their oxides. Then, optical responses of GST, Ge-doped GeTe and Ndoped GeTe films are simulated using Tauc Lorentz law and including the presence of the oxidized upper layer identified by XPS and XRR. Finally, Ge-rich GeTe films before and after crystallization are analyzed using Tauc Lorentz law as well as BEMA. Influence of Ge and $\mathrm{N}$ doping in GeTe optical properties (in terms of gap and refractive index) is then discussed. The comparison between as-deposited samples and annealed samples shows in some case the presence of Ge phases in a GeTe medium. 